\title{
O QUE É ESTRANGEIRIZAÇÃO DA TERRA? Breves apontamentos para compreender o processo de apropriação do território por estrangeiros
}

\author{
WHAT IS LAND FOREIGNIZATION? Brief appointments to \\ understand the process of appropriation of the territory by foreigners
}

\author{
Lorena Izá Pereira \\ Doutoranda do Programa de Pós-Graduação em Geografia \\ Universidade Estadual Paulista (UNESP), Faculdade de Ciências e Tecnologia \\ Pesquisadora do Núcleo de Estudos, Pesquisas e Projetos de Reforma Agrária (NERA) \\ Bolsista da Fundação de Amparo à Pesquisa do Estado de São Paulo (FAPESP) \\ lorena.izap@gmail.com
}

\section{Resumo}

Do mesmo modo que há uma intensificação da corrida mundial por terras há um aumento de pesquisas e publicações sobre o processo de land grabbing, land rush $\mathrm{e}$ estrangeirização da terra, o que possibilita a geração de equívocos e discursos referente a este processo, como a abordagem de land grabbing como sinônimo de estrangeirização da terra. Neste sentido, o objetivo desde trabalho é expor uma construção teórica que permite o entendimento da estrangeirização de terras como um elemento de um processo global de controle de terras, onde a convergência de crises é o principal impulsionador do processo. Compreendemos o controle de terras ao poder de controlar o território (multidimensional e multiescalar) e os recursos a esta associados com a intenção de obter benefícios a partir desse controle, a estrangeirização da terra é o controle do território pelo capital estrangeiro. Esses processos envolvem a territorialização do capital e a desterritorialização e reterritorialização de comunidades camponesas.

Palavras-chave: Land grabbing. Controle de terras. Estrangeirização da terra. Convergência de crises. Território.

\begin{abstract}
Just as there is an intensification of the global land rush, there is an increase in research and publications about land grabbing, land rush and land foreignization, which makes it possible to generate misunderstandings and discourses related to this process, such as the approach of land grabbing as a synonym for land foreignization. In this sense, the objective is to expose a theoretical construction that allows the understanding of the foreignization of lands as an element of a global process of land control, where the convergence of crises is the main driver of the process. We understand the land control as the power to control the territory (multidimensional and multi-scale) and the resources to this associated with the intention to obtain benefits from this control, the foreignization of the land is the control of the territory by the foreign capital. These processes involve
\end{abstract}


the territorialization of capital and the deterritorialization and reterritorialization of peasant communities.

Keywords: Land grabbing. Land control. Land foreignization. Convergence of crises. Territory.

\section{Introdução}

Não há como negar que vivemos um período de intensa corrida mundial por terras. Basta acompanhar as notícias circuladas na mídia nacional e internacional para se tomar consciência do processo, tais como "Enter the new farmers" (REUTERS, 25 jun. 2008); “Investidor estrangeiro busca terra no Brasil" (O ESTADO DE S. PAULO, 10 jul. 2009); "Chineses querem mais terras no Brasil" (FARM LAND GRAB, 27 abr. 2010); entre outras centenas de reportagens publicadas com o objetivo de expressar o alto volume do processo. Junto com a apropriação do território pelo capital estrangeiro emerge uma diversidade de questões debatidas pela academia, instituições multilaterais, organizações não governamentais, movimentos socioterritoriais, empresas e instituições governamentais, com o objetivo de acompanhar essa nova realidade que envolve o território e suas múltiplas dimensões. Neste debate surgem questões tais como: quais são os elementos, fatores e processos que impulsionam a corrida mundial por terras? Ou seja, quais são os drivers desse processo? Quem são os principais agentes (players)? Quais são os países alvos do investimento em terra em larga escala? Quais os impactos? Qual o papel das elites locais? Land Grabbing é sinônimo de estrangeirização da terra? Estes, dentre outros tão importantes questionamentos a respeito do período atual de corrida por terras.

Não há um consenso a respeito do termo utilizado para designar tal processo. Muito se discute sobre land grabbing, land rush e estrangeirização da terra e o único consenso a respeito da temática é o reconhecimento do seu aumento em escala global. Cada pesquisador, instituição, governo e empresa tem uma concepção sobre o processo que varia de acordo com as visões de mundo e intencionalidade, logo, os termos utilizados e elementos debatidos são diferentes em cada concepção. De antemão, adiantamos que nós entendemos o land grabbing e a estrangeirização como processos distintos, porém interligados. Na realidade, baseado nos elementos elencados por Borras Jr., Kay, Gómez e Wilkinson (2012 e 2013), compreendemos o land grabbing como controle de terras, ou 
seja, ao poder de controlar a terra e os recursos a esta associados com a intenção de obter benefícios a partir desse controle, o que significa uma apropriação multidimensional e multiescalar do território envolvendo um novo uso do mesmo, isto é, uma nova territorialidade do capital através de um processo de territorialização, desterritorialização e reterritorialização (T-D-R). Qualquer agente pode exercer o controle de terra, seja este nacional ou estrangeiro, deste modo, a estrangeirização corresponde ao controle de terras pelo capital estrangeiro. Assim, a estrangeirização está inserida em um processo mais amplo de controle de terras.

Neste sentido, o objetivo deste artigo é refletir sobre a definição de estrangeirização da terra em um contexto global de corrida mundial por terras e convergência de crises. Para atingir este objetivo, o estruturamos em duas partes, além dos procedimentos metodológicos e considerações finais. Em um primeiro momento debateremos a respeito da convergência de crises como motor (driver) do processo de controle de terras e de estrangeirização da terra, crises estas oriundas da dinâmica das estratégias de acumulação de capital em um momento de crise de sobreacumulação. $\mathrm{Na}$ segunda parte realizaremos uma breve revisão bibliográfica com os principais autores que discutem a temática e por fim, iremos construir a nossa definição de estrangeirização da terra e os elementos que a caracterizam no período atual, isto é, iremos mostrar como chegamos à definição aqui estabelecida.

\section{Procedimentos metodológicos}

Este artigo é fruto das discussões realizadas durante o estágio de pesquisa de mestrado no laboratório “Agrarian, Food and Environmental Studies", do International Institute of Social Studies (ISS), da Erasmus Rotterdam University, localizado em Haia (Países Baixos) e na disciplina "Politics of Agrarian Transformation", ministrada pelo professor Saturnino Borras Jr. na mesma instituição. Estes debates proporcionaram intercâmbios de ideias e a construção de uma compreensão mais ampla e real sobre os processos de land grabbing, controle de terras e estrangeirização, bem como de outros temas relacionados a questão agrária e economia política agrária atual.

Além das discussões, para a elaboração deste artigo utilizamos uma revisão bibliográfica dos trabalhos publicados e apresentados em conferências sobre o processo de controle de terras e estrangeirização. Priorizamos a diversidade dos trabalhos, logo, 
selecionamos artigos de diferentes áreas do conhecimento, como geografia, história, economia, estudos agrários, relações internacionais, entre outros. Além de artigos científicos, também utilizamos relatórios e documentos de trabalhos publicados por instituições multilaterais e demais organizações, como Banco Mundial, Organização das Nações Unidas para Alimentação e Agricultura (FAO) e Transnacional Institute (TNI). Essa diversidade é importante, pois nos permite compreender que a própria definição sobre estes processos estão em disputa e que cada instituição e pesquisadores apresentam intencionalidades, que podem variar - ou não - de acordo com a sua formação acadêmica e atuação. Enfatizamos a dificuldade de encontrar trabalhos no idioma português, uma vez que embora os países de língua lusófona sejam muito pesquisados, a maioria das pesquisas são executadas por instituições e pesquisadores estrangeiros.

\section{Os drivers do controle de terra e da estrangeirização atual: a convergência de crises}

De acordo com Borras Jr., Kay, Gómez e Wilkinson (2012 e 2013), o traço distintivo do land grabbing atual - que denominamos de controle de terras - é que este ocorre no interior e por causa da dinâmica de estratégias de acumulação de capital que respondem a convergência de múltiplas crises: alimentar, energética, ambiental, climática e financeira. A crise financeira que teve o seu ápice em 2007/2008 nos EUA e Europa é, na realidade, uma resposta à crise de sobreacumulação de 1970 (BORRAS JR., FRANCO, ISAKSON, LEVIDOW e VERVEST, 2015). O ápice no século XXI culminou em uma procura do capital financeiro por novas estratégias e novos negócios mais seguros e rentáveis, ou seja, acentuou a financeirização da agricultura. Compreendemos financeirização como a ascensão dos motivos, mercados, agentes e instituições financeiras nas operações econômicas nacionais e internacionais (EPSTEIN, 2005) e tendência para que a detenção de lucros na economia ocorra cada vez mais através de meios financeiros e cada vez menos através de atividades produtivas (FAIRBAIRN, 2014).

Diante da demanda insuficiente de seus produtos e do declínio dos lucros, as empresas reorientaram seus capitais excedentes das atividades produtivas para o mercado financeiro nos mais variados setores e, recentemente, o alvo é o setor agrícola, especulando sobre as atividades ao longo da cadeia de abastecimento agroalimentar. A crise financeira possibilitou a entrada de um novo agente no processo de controle de 
terras: os fundos de investimento, ou seja, capital portador de juros (CHESNAIS, 2005) e investidores institucionais (FREDERICO, 2016). Atualmente, os fundos de investimento estão em todos os setores da economia, mas cada vez mais na agricultura e no mercado de terras agrícolas (NEWMAN, 2009). Em uma pesquisa rápida realizada no Portal Farm Land Grab', de 12 de maio de 2008 ao dia 06 de abril de 2017 foram publicadas 385 reportagens em escala global sobre investimentos de fundos de pensão na aquisição de terras agrícolas e para a produção agropecuária. Há diferentes tipos de fundos de investimentos: private equity, fundos de pensão, fundos soberanos e fundos hedge (de cobertura), cada um com suas particularidades e riscos.

Estes novos agentes obscurecem o processo de controle de terras, sobretudo no que diz respeito a origem do capital investidor, uma vez que cada vez mais torna-se difícil identificar quem detém ou controla tal fundo, ou seja, quem são os controladores do território e se você não identifica o fundo, você não sabe contra quem está lutando. Além do mais, os investimentos destes agentes, na maior parte, são especulativos e não produtivos, o que pode culminar em consequências para as populações camponesas, como por exemplo o atraso de políticas públicas de reforma agrária. Estes fundos de investimento influenciam e alteram os processos ao longo de toda cadeia produtiva afetando todos aqueles que, de certa forma, vivem da produção agrícola. Enfatizamos que os estudos sobre os fundos de investimento na agricultura e no mercado de terras agrícolas emerge apenas em 2012 e que ainda é extremamente necessário estudos sobre o crescimento deste processo, como destaca Ouma (2014).

Ao mesmo tempo, vivemos um período de crise e/ou receio ${ }^{2}$ de uma futura crise energética proporcionada por diferentes fatores, como pautado em um discurso de aquecimento global oriundo da utilização de combustíveis fósseis, esgotamento gradual das fontes de petróleo e instabilidade política na relação com os países produtores deste recurso. Segundo Fernandes, Welch e Gonçalves (2014, p. 51) "a crise do petróleo têm colocado em questão o futuro da produção de energia, fazendo com que governos e empresas invistam na terra para produzir agrocombustíveis". Tais fatores fazem com que empresas transnacionais e Estados passem a investir em fontes alternativas de produção de energia. É neste cenário de uma mudança na matriz energética que o interesse em terras agricultáveis emerge no sentido de uma segurança energética. No caso do Brasil, a produção de agrocombustíveis se dá através da cana-de-açúcar. 
A partir dos anos 2000 inicia-se a apropriação de terras para o cultivo de cana-deaçúcar, anterior à crise financeira. Tomamos o exemplo do Brasil. Segundo dados da Pesquisa Agropecuária Municipal (PAM), do Instituto Brasileiro de Geografia e Estatística (IBGE), em 2001 o Brasil possuía 5.022.490 hectares destinados ao cultivo de cana, com uma produção de 344.292.922 toneladas. Em 2009, cerca de dois anos após o início da crise financeira, a área plantada alcançou 8.845.833 hectares e a produção 691.606.147 toneladas. Já no ano de 2015, a área produzida foi de 10.161 .622 e a produção de 748.636.167, ou seja, de 2001 a 2015 a produção desta commodity mais que dobrou. Estes dados evidenciam que novas terras foram incorporadas à produção de canade-açúcar e terras que antes eram utilizadas para outros cultivos (sobretudo alimentares), também foram incorporadas pelo setor sucroalcooleiro para a produção de cana. Deste modo, há uma territorialização da commodity cana e a desterritorialização de culturas destinadas a produção de alimentos, possibilitando o surgimento de uma outra crise: a crise alimentar.

No caso da crise alimentar, além de ser propiciada pela preocupação de substituição de terras para o cultivo de cana, soja e outras commodities, há uma preocupação com o aumento da população mundial. A FAO em 2009 divulgou um documento intitulado "Global agricutulre towards 2050”, afirmando que em 2050 a população mundial está projetada para nove bilhões de habitantes. $\mathrm{O}$ cálculo "um maior número de bocas para alimentar somado com a diminuição de terras destinadas a produção de alimentos" causou e ainda causa muitas preocupações por parte de instituições multilaterais e governos, que buscam adquirir terras em outros países para a produção de alimentos e garantia de uma segurança alimentar, como é o caso dos Países do Golfo que adquirem terras para a produção agrícola, uma vez que com a crise do petróleo de 1973 sofreram uma forte crise alimentar (WOERTZ, 2013) e Cabo Verde, que em 1989 adquiriu 10.000 hectares de terras no Paraguai para a produção de alimentos, pois segundo relatórios técnicos, Cabo Verde não possui condições de produzir alimentos para alimentar sua população (PEREIRA, 2016).

Contudo ressaltamos que há falsos discursos em torno da questão. Empresas (trans) nacionais e até mesmo governos aproveitam da situação e buscam terras para a produção de commodities em larga escala com a justificativa de propiciar a segurança alimentar, quando apenas estão à procura de novas fontes de acumulação de capital, 
justamente devido à crise financeira. É importante considerar que a crise não é que haja produção de alimentos insuficiente, mas sim envolve o aumento nos preços de alimentos, conhecido como agroinflação. Como já salientou Josué de Castro em seu livro "Geografia da Fome" (1984), o problema da fome não é de produção e sim uma questão econômica de acesso ao alimento.

Outras crises que surgem nesse contexto são ambiental e climática, que estão diretamente relacionadas com a crise energética, pois o discurso do aquecimento global, das mudanças climáticas e do aumento no buraco da camada de ozônio está relacionado com a emissão de gases poluentes oriundos de combustíveis fósseis. Essa crise proporciona o Green Grabbing, ou seja, emersão de apropriações verdes através de florestas plantadas, mercado de carbono e $\mathrm{REDD}^{+}{ }^{3}$, pautado no discurso de proteção ambiental. Um ponto interessante que Fairhead, Leach e Scoones (2012) expõem é que as commodities produzidas são cada vez mais discursivas, ou seja, são produzidas porque há um discurso da mídia, da ciência e da política.

Os mesmo autores afirmam que vivenciamos uma economia de reposição, ou seja, antes a natureza era valorizada por aquilo que oferecia e hoje ela é valorizada pelo sua reposição, pois há a reposição dos danos causados, o que gera crescimento econômico, há uma dupla valorização da natureza. Deste modo, há uma commoditização da natureza. Várias empresas hoje adquirem terras com esta intencionalidade e de fato a natureza tornou-se uma mercadoria. Tomamos o exemplo do Paraguai, onde há a Lei n. 352/1994 que delimita áreas silvestres protegidas. No Artigo 56 da referida lei é estabelecido que áreas silvestres não podem ser expropriadas e são isentas de impostos. Segundo Barreto (2013), qualquer proprietário pode declarar que sua propriedade rural é uma área silvestre protegida, incluindo terras que são griladas. Essa prática em prol da natureza acaba legalizando propriedades ilegítimas e desterritorializando comunidades, sobretudo indígenas no Paraguai.

Destacamos que todas estas crises são essenciais para explicar o processo de controle de terras e consequentemente a estrangeirização da terra e não podem ser compreendidas separadamente, mas sim em um contexto de complexificação das estratégias do capital para investimentos mais seguros e com retornos financeiros elevados. Contudo, devemos compreender que estas crises fazem parte de processos mais amplos da economia política internacional (FREDERICO, 2016). 
Sintetizando, a crise financeira de 2007/2008 gerou incertezas aos investidores devido aos retornos negativos sobre os ativos convencionais e níveis crescentes de inflação. Simultaneamente, os processos de aumento da população mundial, mudança na dieta alimentar mundial, crescimento na demanda por agrocombustíveis - inclusive impulsionado pelas políticas públicas de países emergentes como o Brasil e discurso em torno de uma mudança climática tornaram os investimentos em terras agrícolas e na agricultura atrativos ao capital financeiro (OUMA, 2014; VISSER, 2015; FREDERICO, 2016). É neste cenário de neoliberalismo, globalização e convergência de crises e consequente crescimento dos fundos de investimento na agricultura que o processo de controle de terras e estrangeirização são intensificados e apresentam novos elementos e logo novas práticas de resistências. O principal diferencial do processo de controle de terras atual daquele ocorrido em outros períodos é a lógica financeira presente nas aquisições (FREDERICO, 2016) e a convergência global de crises. A convergência de múltiplas crises afeta o capital nacional e internacional e a partir do momento que compreendemos que a ascensão do controle de terras é uma resposta a convergência de múltiplas crises, tanto o capital nacional e quanto o internacional, são capazes de produzir respostas a estas, deste modo a estrangeirização

\section{Debate sobre o controle de terras em nível global}

Concomitante a expansão do processo de controle de terras, há uma intensificação do debate sobre o mesmo. Pesquisadores de diferentes áreas do conhecimento, instituições governamentais e multilaterais e movimentos sociais se dedicam a pesquisa do tema. Como Holt-Giménez (2012) expressou, "land grabbing [controle de terras] é manchete". Neste debate o único consenso é que o controle de terras é um processo em expansão, ademais há uma grande discussão sobre os elementos que ajudam a entender o controle de terras, inclusive como se referir ao mesmo. Neste sentido, apresentaremos algumas definições sobre o controle de terras - land grabbing, acaparamiento de tierras, corrida mundial por terras, land rush e land control. Procuramos selecionar visões de diferentes áreas do conhecimento e de diferentes países para que pudéssemos proporcionar um debate amplo e fidedigno.

Começaremos pela Organização das Nações Unidas para Alimentação e Agricultura (FAO), para quem o Land Grabbing deve necessariamente envolver três 
elementos fundamentais: transações em grandes escalas, neste caso acima de 10.000 hectares; participação de governos estrangeiros, tanto na compra quanto na venda de terras em larga escala; terras adquiridas devem ser destinadas a produção de alimentos básicos, neste caso, produção de commodities como cana-de-açúcar para agrocombustíveis, mas com especificações (FAO, 2012). Deste modo, observa-se a estreita relação entre land grabbing, estrangeirização e concentração da terra. O High Level Panel of Experts on Food Security and Nutrition (HLPE), da FAO, no documento intitulado "Land Tenure and International Investments in Agriculture", publicado em 2011, afirma que o Land Grabbing é um processo que remonta os tempos coloniais e é impulsionado atualmente devido à demanda por alimentos, agrocombustíveis e minerais. Ressalta o debate ideológico no processo de Land Grabbing e enfatiza o papel do Estado como controlador desse processo e que se este for feito com consciência poderá gerar benefícios para as populações locais.

O economista Klaus Deininger (2011) utiliza o termo land rush como o interesse estrangeiro na posse da terra, entende o mesmo como um processo antigo, mas que assume uma postura diferente recentemente. No entanto, Deininger (2011) parte de uma perspectiva que o investimento estrangeiro em terras agrícolas, se realizado de modo consciente, poderá trazer benefícios para os países anfitriões, inclusive elenca as vantagens do mesmo: infraestrutura social, geração de empregos e postos de trabalho, permite o acesso ao mercado e tecnologias pelos agricultores locais. Ressaltamos que Klaus Deininger (2011) é economista do Banco Mundial e um dos autores do tão debatido e controverso relatório "Rising Global Interest in Farmland: Can it yield sustainable and equitable benefits?".

Von Braun e Meinzen-Dick (2009), partem da concepção que a aquisição de terras em países em desenvolvimento para a garantia da segurança alimentar é um efeito da crise de alimentos. Os principais investidores são países que têm pouca terra agricultável e água, porém apresentam muitos recursos financeiros e países com população grande. Um ponto interessante que os autores trazem para o debate é que a proximidade geográfica e condições climáticas aptas para a produção de culturas básicas preferenciais, ou seja, os investimentos, vão para os locais nos quais as culturas que os países mais têm interesse melhor se desenvolvem. A procura para a produção de agrocombustível também impulsiona esta corrida por terras. Os autores afirmam que embora os investimentos nos 
países em desenvolvimento sejam bem vindos, a escala e a velocidade dos investimentos criam algumas oposições. Estes mesmos autores veem a aquisição de terras em larga escala como uma possível oportunidade para geração de empregos, para redução da pobreza e construção de infraestruturas. A instabilidade sócio-política dos países em desenvolvimento também pode criar riscos. Para os autores, se os pequenos produtores se unirem conseguirão usufruir do processo desta corrida mundial por terras, pois os investimentos dependem de como os mesmo são concebidos e geridos. Os elementos citados por estes autores nos permite caracterizá-los no Paradigma do Capitalismo Agrário.

Peluso e Lund (2011), utilizam o termo Land Control para abordar o referido processo, entendendo que o mesmo corresponde a novas práticas que consolidam formas de acesso à terra, consistindo em uma recriação da governança da terra devido ao grande interesse de estruturas empresariais atuantes em escala global. Peluso e Lund (2011) compreendem que a aquisição de terras por estrangeiros não aumentou, apenas possui novos mecanismos para a sua efetivação, como novos agentes, mecanismos para apropriação, novas relações de trabalho e novos usos do solo.

Sérgio Sauer $(2010 ; 2011)$, utiliza a palavra estrangeirização como um novo ciclo da expansão do capital que tem como resultado o aumento dos números de conflitos territoriais e fundiários, além de uma elevação no preço da terra, que impacta diretamente as políticas de caráter agrário. Ou seja, a estrangeirização não é um fenômeno novo segundo Sauer (2010; 2011) e sim cíclico, diferentemente do que defendem Peluso e Lund (2011). Em outro trabalho de Sérgio Sauer e Sérgio Pereira Leite (2012), o mesmo processo é abordado como uma corrida mundial por terras intensificada a partir de 2008, sobretudo pelo interesse na produção de agrocombustíveis. Entendem o mesmo como um processo antigo, mas que adquire novas dinâmicas. Sauer e Leite (2012) ainda destacam que a corrida mundial por terras ocorre, principalmente, através da produção de oito commodities: arroz, cana-de-açúcar, canola, dendê (óleo), floresta plantada (eucalipto e pinus), girassol, milho e soja. Borras Jr, Franco e Wang (2012) abordam estas como commodities flexiveis, ou seja, aquelas culturas que apresentam múltiplos usos e por isso possuem grande interesse na sua produção. Em 2016, Sauer em parceira com Borras Jr. publicou o artigo intitulado "Land Grabbing e Green Grabbing: uma leitura da 'corrida na produção acadêmica' sobre a apropriação global de terras". Os autores utilizam a 
expressão apropriação de terras para abordar o Land Grabbing, devido ao debate em torno da semântica da palavra e da sua tradução para o português.

Outro elemento bastante debatido nas pesquisas sobre o controle de terras é a historicidade do processo. Sassen (2013) entende o Land Grabbing como um processo antigo, que faz parte da humanidade, mas que em cada fase é marcado por uma particularidade. A nova fase teve seu início pelo menos há cem anos e a marca dessa fase atual do Land Grabbing é o interesse na produção de agrocombustíveis. Fernandes (2011) também elenca os agrocombustíveis como um elemento essencial para entender esta nova etapa do processo. Borras Jr. e Franco (2010 e 2012) compreende o Land Grabbing como um novo ciclo de desapropriação promovido pelo capital que se eleva devido as crises. Já Oliveira $(2010 ; 2011)$ parte da perspectiva que o processo de estrangeirização é o mesmo do século XX e que não foi impulsionado por novos elementos como os agrocombustíveis ou convergência de crises.

Outro aspecto interessante do trabalho de Sassen (2013) é a distinção que a autora realiza entre o imperialismo do século XIX e XX e o Land Grabbing do século XXI, afirmando que atualmente todo Estado-Nação é soberano, por mais fraca que seja esta soberania. A mesma autora afirma que as redes transnacionais sejam governos ou empresas transnacionais, controlam parcelas de terras em outras nações, levando a desmontagem do território nacional, a fragmentação deste, "uma remontagem espacial". Deste modo, o land grabbing é uma montagem territorial e, ao mesmo tempo, é uma desmontagem da soberania nacional. Por fim, Sassen (2013) expressa o land grabbing como a expressão de uma mudança geopolítica. Neste ponto, retomamos a geógrafa Bertha Becker (2000), que crítica a abordagem tradicional da geopolítica - isto é aquele viés que compreende apenas o Estado como agente geopolítico - e nos coloca a necessidade de considerar novos agentes, processos e dinâmicas. Desta forma, a estrangeirização seria um antigo processo, mas com novas dinâmicas que é de total importância para uma retomada da geopolítica.

Olivier de Schutter (2011) utiliza o termo Land-Grabbing como alocação ou aquisição de terras a longo prazo por investidores. Argumenta em um sentido contrário ao Banco Mundial, afirmando que a fraca governança da terra não é o único problema referente ao Land-Grabbing. Ainda expressa que as tentativas atuais de regular investimentos em larga escala em terras agrícolas são enganosas na medida em que 
pressupõem que tais investimentos passam a ser desejáveis desde que sejam bem geridos. Não precisamos regular o Land-Grabbing, como se fosse algo inevitável, precisamos de um plano alternativo para o investimento agrícola (SCHUTTER, 2011) e pelo fato de ser inevitável, o autor afirma que estes investimentos devem beneficiar a população rural local e não ser uma transferência de recursos para os países desenvolvidos.

O economista com foco nas políticas de transformações agrárias A. Haroon Akram-Lodhi (2012), utiliza o termo Land Grabbing para defender uma forma especifica de aquisições de terras corporativa. Para Akram-Lodhi (2012) land grabbing corresponde apenas a aquisições de terra (compra e arrendamento) para fins agrícolas, assim, aquisição de terras para mineração ou indústria não é caracterizado como land grabbing. $\mathrm{O}$ autor também propõe uma distinção interessante entre os investimentos do setor financeiro, do setor industrial e agrícola, ou seja, há uma clara diferença entre o objetivo de cada setor ao adquirir terras. Para o setor que compra a terra para produção agrícola diretamente, a fraca governança da terra é interessante, mas para aqueles que investem indiretamente (fundos) não é tanto assim. Por fim, Akram-Lodhi (2012) destaca que a crise de alimentos não explica o land grabbing, até porque não há uma crise na produção de alimentos e sim uma crise no abastecimento. Há uma mudança na política agrária que reflete no land grabbing.

Na ciência geográfica, Fernandes (2011), entende a estrangeirização como processo de compra, arrendamento ou qualquer outro tipo de apropriação do território agrícola pelo capital internacional, como uma nova característica da procura de novos territórios para a expansão da agricultura capitalista. $\mathrm{O}$ autor compreende que a estrangeirização está relacionada com crise de aumento dos preços dos alimentos e dos combustíveis. Estamos vivendo um momento de mudança estrutural na produção de energia, em que se eleva o interesse na aquisição de grandes extensões de terra para o cultivo de commodities que são matéria-prima para a produção de agrocombustíveis. $\mathrm{O}$ campo produtor de alimentos e fibras passa a produzir cada vez mais energia (FERNANDES, 2011). Em outro artigo Clements e Fernandes (2013), compreende a estrangeirização da terra a partir da Geopolítica da Questão Agrária, afirmando que a estrangeirização da terra e a questão agrária viraram tema no debate sobre a soberania nacional. 
Ainda para estes autores, o processo de estrangeirização da terra é gerador de concentração fundiária e que a questão fundamental são os impactos nos territórios camponeses, ressaltando o papel do Estado e a elevação exacerbada do preço da terra. Enfatizam também que o Brasil, além de ser alvo desta grilagem global, empresas e latifundiários brasileiros buscam a sua territorialização em outros países, como Paraguai (PEREIRA, 2016), Bolívia (McKAY, 2017) e Moçambique (CLEMENTS, 2015).

Oliveira $(2010 ; 2011 ; 2014)$ aborda a respeito da estrangeirização referindo-se a esta como "mundialização monopolista da agropecuária no mundo", na qual empresas multinacionais não estão se tornando proprietárias das terras agricultáveis, mas sim controladoras monopolistas da produção agrícola. Defende que "em termos mundiais há movimentos de capitais na direção de aquisição de terras no universo capitalista neste período histórico, mas ele não é tão diferente do que ocorreu no século XX”. Logo, segundo Oliveira (2010) não há peculiaridades neste processo, inclusive o autor expõe que a estrangeirização da terra é uma farsa do atual governo brasileiro para retirar o foco da reforma agrária.

Por fim, ainda na Geografia Gustavo de Lima Torres de Oliveira (2016) também se dedica a temática analisando os investimentos de capital chinês na agricultura brasileira. $\mathrm{O}$ autor traduz o termo land grabbing para o português como 'corrida mundial por terras', conceitualizando-o como uma reavaliação dramática da propriedade fundiária após o surto nos preço das commodities agrícolas em 2007/2008. Oliveira (2016) também ressalta as contradições no sentido que afirmar que apenas países ricos em capital e pobres em terras praticam o controle de terras, quebrando a lógica Sul-Pobre-Expropriado e Norte-Rico-Expropriador, o que já foi enfatizado por Feodoroff (2013) e Ploeg, Franco e Borras Jr. (2015).

Através do debate e reflexões sobre estas definições selecionadas entendemos o land grabbing, acaparamiento de tierras, land rush ou corrida mundial por terras como um processo global de controle de terras. O controle de terras se refere ao poder de controlar a terra e os recursos a esta associados - qualidade do solo, biodiversidade, recursos naturais e minerais - com a intenção de obter vantagens a partir desse controle. Esta apropriação pode ser realizada através de múltiplas estratégias, tais como: compra do imóvel rural, arrendamento, contrato de parceria, contrato de gaveta, estratégias das corporações em constituírem empresas em nome de terceiros e que possuam uma 
identidade nacional, táticas de fusões e joint venture entre empresas nacionais e transnacionais (como o exemplo da Veracel Celulose - joint venture entre Stora Enso e Fibria), das empresas de capital aberto e com ações Free Float, ou seja, ações destinadas a livre circulação, da concessão pública para a exploração do uso de superfície. Cada vez mais, os mecanismos e as estratégias utilizadas pelo capital para acessar e controlar o território são mais sofisticadas e não exigem necessariamente a posse legal da terra, isto é, o capital não precisa comprar uma propriedade para controlá-la, há um controle da territorialidade, ou seja, do uso do território.

É importante destacar que compreendemos por apropriação o ato de tornar próprio ou conveniente, de adaptar, de adequar, apoderar-se, apossar-se de um território, neste caso do segundo território. Considerando o território na sua multidimensionalidade e multiescalaridade, o controle de terras proporciona novas territorialidades do capital e promove os processos de territorialização, desterritorialização e reterritorialização, pois a territorialização de uma empresa implica na desterritorialização de camponeses e indígenas que, por sua vez, se reterritorializam em outras áreas ou em periferias urbanas.

Os elementos essenciais para compreender o controle de terras no contexto atual são: intensificação do processo em escala global, sobretudo envolvendo a ação do capital estrangeiro, com novas formas de apropriação do território e novos impactos; simultaneidade e atuação global; consolidação do neoliberalismo; sobreacumulação; criação de uma rede de capital, na qual diferentes agentes atuam - empresas de capital internacional, empresas nacionais, governos, fundos de investimento e latifundiários; aumento do interesse na produção de commodities flexíveis, sobretudo para a produção de agrocombustíveis e convergência de crises, inclusive em um contexto de mudança de um paradigma alimentar.

Neste sentido, a estrangeirização da terra é um elemento que compõe um processo maior de controle de terras. A estrangeirização corresponde ao controle do território pelo capital estrangeiro. Enfatizamos que a estrangeirização não exclui os agentes domésticos, como empresas nacionais, agricultores locais, sociedade civil e até mesmo o Estado, uma vez que os acordos envolvendo transações de terras são moldados pelas ações e interesses daqueles que possuem poder social (FAIRBAIRN, 2013). Partimos dessa concepção, pois se o controle de terras é uma resposta do capital a convergência de crises, qualquer tipo de capital (nacional ou estrangeiro, produtivo ou financeiro) é afetado com a convergência 
de crises e todos respondem a convergência de crises via controle de terras, logo, não é apenas uma reação do capital estrangeiro. Ocorre que cada capital é afetado de uma maneira e responde de modo distinto, por isso há uma variedade de agentes - e articulação entre estes, formando uma rede com o objetivo de controlar o território -, formas de apropriação e interesses no processo de controle de terras.

Não se deve reduzir a estrangeirização da terra a mera quantidade de hectares em posse de capitais estrangeiros, não que isso não seja importante devido ao controle do território, porém, temos que ir além e considerar os impactos deste processo, uma vez que a população do país é negligenciada em prol de um modelo de desenvolvimento para o capital. Devemos considerar quais terras são apropriadas para a territorialização do capital, os recursos, os conflitos e quem está sendo desterritorializado - isto mostra a multidimensionalidade do território. Oliveira $(2010,2011)$ expõe críticas ao afirmar que a estrangeirização é uma "farsa" para tirar o foco da questão agrária e Marques (2011, p. 12) afirma que a estrangeirização da terra deu um novo significado a questão agrária, no qual a "questão agrária resulta da estrangeirização da terra e regime alimentar corporativo". A estrangeirização da terra é um novo elemento que se configura como estrutural. Assim, a reforma agrária não foi superada ou escamoteada com a ascensão da estrangeirização da terra, como aponta Oliveira (2011), mais sim emerge um novo elemento estrutural que dificulta o acesso à terra pelo campesinato em escala global. A reforma agrária é a uma das políticas contra a estrangeirização da terra, pois o enfraquecimento de programas de acesso à terra e de reforma agrária auxilia na consolidação da estrangeirização. Porém, acima de tudo, a luta dos movimentos sociais por um modelo de desenvolvimento alternativo é cada vez mais urgente e é a via mais eficaz na luta contra o controle de terras, estrangeirização e desterritorialização de comunidades camponesas e indígenas para a territorialização do agronegócio estrangeiro.

\section{CONSIDERAÇÕES FINAIS}

Land grabbing, como é abordado por acadêmicos e instituições internacionais, não é sinônimo de estrangeirização da terra, termo que muito é frequente utilizado no Brasil para se referir ao processo de controle de terras. A estrangeirização da terra está inserida em um processo maior de controle de terras, ou seja, poder de controlar as terras e demais recursos a ela associados, como a água, biodiversidade, mineração e demais. A 
estrangeirização da terra é um processo antigo, sobretudo na América Latina (BORRAS JR., KAY, GÓMEZ e WILKINSON, 2012; 2013) e que emerge no século XXI inserido em um contexto de controle de terras com diversos aspectos novos - fundos de investimento como agentes na apropriação de terras; novas escalas de apropriação de terras e de capital; financeirização da agricultura; agronegócio globalizado e impactos territoriais, gerando novas territorialidades e culminando no processo de territorialização; desterritorialização e reterritorialização - que torna a estrangeirização da terra como um elemento estrutural para a questão agrária atual e para o desenvolvimento territorial nos países estudados durante a pesquisa de mestrado. Emerge novas estratégias técnicas para a territorialização e de discurso, a fim de justificar a apropriação de terras em grande escala. Qualquer agente pode exercer o controle de terra, seja este nacional ou estrangeiro, desde modo, a estrangeirização corresponde ao controle de terras pelo capital estrangeiro. Assim, a estrangeirização está inserida em um processo mais amplo de controle de terras.

Emergem novos agentes no processo e antigos assumem novos papéis, exemplos são fundos de investimentos que passam investir cada vez mais na aquisição de terras; empresas de capital internacional - globais e regionais - que se territorializam sobretudo em países subdesenvolvidos e em vias de desenvolvimento; os agentes nacionais assumem novas funções e se tornam mais essenciais para a territorialização do capital internacional em seus países; os Estados, que embora não adquiram terras diretamente, possuem empresas estatais e fundos soberanos para tal ação; os Estados são cruciais, pois cada vez mais exercem funções de impulsionar investimentos internacionais na agricultura e, ao mesmo tempo e em alguns casos, garantir que tais investimentos não afetem negativamente.

Além de considerar o processo de controle de terras e consequentemente a estrangeirização a partir da economia política, que segundo Franco, Borras Jr., AlonsoFradejas, Buxton, Herre, Kay e Feodoroff (2013) é a lente mais adequada para analisar tal processo, é necessário entender a apropriação de terras pelo capital a partir de uma leitura geográfica. Assim, compreendemos que o controle da terra produz impactos diretos no território, uma vez que há a territorialização da monocultura ou de empresas para a especulação imobiliária, com utilização cada vez mais intensa de sementes transgênicas e agroquímicos, que desterritorializam culturas alimentares, causam danos imensos ao meio ambiente e a saúde humana. Comunidades inteiras são 
desterritorializadas, o preço da terra aumenta, pois a demanda é alta, logo, a concentração de terra aumenta. A estrangeirização ainda produz efeitos no território imaterial, uma vez que há uma disputa entre lógicas de mercado e produção, há uma disputa de modelo de desenvolvimento: a estrangeirização, através do agronegócio versus o modelo camponês. Tomando como exemplo o caso Sul-Americano, observa-se a ascensão ao poder de uma elite conservadora e neoliberal que tem como postura política a liberação da apropriação de terras pelo capital estrangeiro e criminalização de movimentos sociais de luta pela terra, como ocorre no Brasil com o governo de Michel Temer (PMDB), Paraguai com Horacio Cartes (Partido Colorado) e Argentina com Mauricio Macri (Proposta Republicana).

\section{Notas}

1 Pesquisa realizada no dia 06 abr. 2017. Disponível em: http://www.farmlandgrab.org/search?page=1\&query=pension+fund\&sort_order=date. Acesso em: 11 abr. 2017.

${ }^{2}$ Ressaltamos como 'receio' devido ao incessante discurso em torno dos agrocombustíveis enquanto fonte de energia sustentável e em relação as relações políticas cada vez mais instáveis com os países produtores de fontes de energia fosseis, como o petróleo, o que pode gerar um crise no futuro.

${ }^{3}$ Redução de Emissões provenientes de Desmatamento e Degradação florestal. Segundo o Ministério do Meio Ambiente (MMA), corresponde a arquitetura internacional de pagamento por resultados nacionais comprovados de redução de emissões provenientes de desmatamento, degradação florestal, manejo sustentável de florestas e manutenção e aumento dos estoques de carbono. Disponível em: $<$ http://redd.mma.gov.br/>. Acesso em: 22 out. 2016.

\section{REFERÊNCIAS}

AKRAM-LODHI, A. Haroon. Contextualising land grabbing: contemporary land deals, the global subsistence and the world food system. Canadian Journal of Development Studies. v. 33, n. 02, p. 119-142, 2012.

BARRETO, Mirta. La lucha por la tierra frente las corporaciones y el Mercado. Asunción: Centro de Servicios y Estudios Rurales (CSER), 2013.

BECKER, Berta. A Geopolítica na Virada do Milênio: Logística e desenvolvimento sustentável. CASTRO, Iná Elias de; CORRÊA, Roberto Lobato; GOMES, Paulo Cesar da Costa (Org.). Geografia: Conceitos e Temas. Rio de Janeiro: Editora Bertrand Brasil. 2005, p. 271-307.

BORRAS JR., Saturnino; FRANCO, Jennifer. Towards a Broader View of the Politics of Global Land Grab: rethinking land issues, reframing resistance. ICAS Working Paper Series, 2010. 
BORRAS JR., Saturnino; FRANCO, Jennifer. Global Land Grabbing and trajectories of agrarian change: a preliminary analysis. Journal of Agrarian Change, v. 12, n. 01, p. 34-59, 2012.

BORRAS JR., Saturnino; FRANCO, Jennifer; WANG, Chunyu. Tendencias políticas en disputa para La gobernanza global del acaparamiento de tierras. Amsterdam: Transnational Institute, 2012.

BORRAS JR, Saturnino; KAY, Cristóbal; GÓMEZ, Sergio; WILKINSON, John. Land grabbing and global capitalism accumulation: key features in Latin America. Canadian Journal of Development Studies, v. 33, n. 04, p. 402-416, 2012.

BORRAS JR, Saturnino; KAY, Cristóbal; GÓMEZ, Sergio; WILKINSON, John. Acaparamiento de tierras y acumulación capitalista: aspectos clave en América Latina. Revista Interdisciplinaria de Estudios Agrarios, v. 38, n. 01, p. 75-103, 2013.

BORRAS JR.; Saturnino; FRANCO, Jennifer; ISAKSON, Ryan; LEVIDOW, Les; VERVEST, Pietje. The rise of flex crops and commodities: implications for research. The Journal of Peasant Studies, v. 43, n. 1, p. 93-115, 2015.

CASTRO, Josué de. Geografia da fome. O dilema brasileiro: pão ou aço. Rio de Janeiro: Edições Antares, 1984.

CLEMENTS, Elizabeth Alice; FERNANDES, Bernardo Mançano. Land Grabbing, Agribusiness and the Peasantry in Brazil and Mozambique. Agrarian South: Journal of Political Economy, v. 41, n. 02, p. 41-69, 2013.

CLEMENTS, Elizabeth Alice. Brazilian Polices and Strategies for rural territorial development in Mozambique: South-South Cooperation and the case of ProSAVANA and PAA. Presidente Prudente, 2015, 278 f. Dissertação (Mestrado em Geografia) Faculdade de Ciências e Tecnologia, Universidade Estadual Paulista "Júlio de Mesquita Filho", Presidente Prudente, 2015.

CHESNAIS, François. O capital portador de juros: acumulação, internacionalização, efeitos econômicos e políticos. CHESNAIS, François (Org.). A finança mundializada: raízes sociais e políticas, configuração, consequências. São Paulo: Boitempo Editorial, 2005. p. 35-67.

DEININGER, Klaus. Challenges posed by new wave of farmland investment. The Journal of Peasant Studies, v. 30, n. 02 p. 217-247, 2011.

DEININGER, Klaus; BYERLEE, Derek; LINDSAY, Jonathan; NORTON, Andrew; SELOD, Harris; STICKLER, Mercedes. Rising Global Interest in Farmland: Can it yield sustainable and equitable benefits?. Washington D.C.: The World Bank, 2011.

EPSTEIN, Gerald A. Financialization and the world economy. Cheltenham: Edwar Elgar, 2005. 
FAIRBAIRN, Madelaine. 'Like gold with yield': evolving intersections between farmland and finance. The Journal of Peasant Studies, v. 41, n. 05, p. 777-795, 2014.

FAIRBAIRN, Madelaine. Indirect dispossession: domestic power imbalances and foreign access to land in Mozambique. Development and Change, v. 44, n. 02, p. 335-356, 2013.

FAIRHEAD, James; LEACH, Melissa; SCOONES, Ian. Green Grabbing: a new appropriation of nature? The Journal of Peasant Studies, v. 39, n. 02, 237-261, 2012.

FARM LAND GRAB. Chineses querem mais terras no Brasil. Portal Farm Land Grab, publicado em: 27 abr. 2010, disponível em: $<$ http://www.farmlandgrab.org/post/view/15504-chineses-querem-mais-terras-nobrasil>. Acesso em: 11 abr. 2017.

FEODOROFF, Timothé. Quelques clés de lecture pour compendre et analyses l'accaparement des terres. Revue Possibles, p. 12-22, 2013.

FERNANDES, Bernardo Mançano. Estrangeirização de terras na nova conjuntura da questão agrária. Conflitos no Campo Brasil 2010. Goiânia: Comissão Pastoral da Terra (CPT), 2011.

FERNANDES, Bernardo Mançano; WELCH, Clifford Andrew; GONÇALVES, Elienai Constantino. Land Governance in Brazil: a geo-historical review of land governance in Brazil. Roma: International Land Coalition, 2012.

FRANCO, Jennifer; BORRAS JR., Saturnino; ALONSO-FRADEJAS, Alberto; BUXTON, Nick; HERRE, Roman; KAY, Sylvia; FEODOROFF, Timothé. L'Accaparement des terras: un livret. Amsterdam: Transnational Institute, 2013.

FREDERICO, Samuel. Território, Capital Financeiro e Agricultura. Investimentos financeiros estrangeiros no agronegócio brasileiro. Relatório de Pós Doutorado. Laboratoire Dynamiques Sociales et Recomposition des Espaces (Ladyss), Universidade Paris 8, 213 f, 2016.

HLPE. Land Tenure and International Investments in Agriculture. Roma: High Level Panel of Experts on Food Security and Nutrition, 2011.

HOLT-GIMÉNEZ, Eric. Land grabs versus land sovereignty. Food First Backgrounder, n. 18, v. 4, p. 01-03, 2012.

IBGE. Produção Agrícola Municipal (PAM). Instituto Brasileiro de Geografia e Estatística. Disponível em: $<$ http://www.ibge.gov.br/home/estatistica/economia/pam/2015/default.shtm>. Acesso em: 20 mar. 2017.

MARQUES, Marta Inez Medeiros. O novo significado da questão agrária. Anais do V Simpósio Internacional e VI Simpósio Nacional de Geografia Agrária - SINGA, Belém, p. 01-12, 2011. 
McKAY, Ben. The politics of control: new dynamics of agrarian change in Bolivia's soy complex, 2017, $290 \mathrm{f}$. Tese (PhD in Agrarian Studies) - International Institute of Social Studies, Erasmus University Rotterdam, The Hague, 2017.

NEWMAN, Susan. Financialization and changes in the social relations along commodity chains: the case of coffee. Review of Radical Political Economics, v. 41, n. 04, p. 539$559,2009$.

O ESTADO DE S. PAULO. "Investidor estrangeiro busca terras no Brasil". Jornal O Estado de S. Paulo, caderno Economia, publicado em: 10 jul. 2009, disponível em: $<$ http://economia.estadao.com.br/noticias/geral,investidor-estrangeiro-busca-terras-nobrasil,400617> Acesso em: 11 abr. 2017.

OLIVEIRA, Ariovaldo Umbelino de. A questão da aquisição de terras por estrangeiros no Brasil - um retorno aos dossiês. Revista Agrária, n.12, p. 03-113, 2010.

OLIVEIRA, Ariovaldo Umbelino de. Tragédia e farsa, a compra de terras por estrangeiros. Jornal Le Monde Diplomatique Brasil, 02 set. 2011.

OLIVEIRA, Ariovaldo Umbelino de. A mundialização da agricultura brasileira. OLIVEIRA, Ariovaldo Umbelino de; LIRA, Elizeu Ribeiro; CABRAL, José Pedro Cabrera; SANTOS, Roberto de Souza (Org.). Território em Conflito, Terra e Poder. Goiânia: Kelps, 2014, p. 17-103.

OLIVEIRA, Gustavo de Lima Torres. Regularização fundiária e a "corrida mundial por terras" no Brasil. Revista Campo Território, Ed. Especial Land Grabbing, Grilagem e Estrangeirização de terras, n. 23, v. 11, p. 43-75, 2016.

ORGANIZAÇÃO DAS NAÇÕES UNIDAS PARA A ALIMENTAÇÃO E AGRICULTURA. Global agriculture towards 2050. Roma: FAO, 2009.

ORGANIZAÇÃO DAS NAÇÕES UNIDAS PARA A ALIMENTAÇÃO E AGRICULTURA. Dinámicas del mercado de la tierra en América Latina y el Caribe: concentración y extranjerización. Roma: FAO, 2012.

OUMA, Stefan. Situating global Finance in the land rush debate - A critical review. Geoforum, n. 57, p. 01-14, 2014.

PELUSO, Nancy Lee; LUND, Christian. New frontiers of land control: introduction. The Journal of Peasant Studies, v. 38, n. 04, p. 667-681, 2011.

PEREIRA. Lorena Izá. A presença brasileira e argentina na aquisição de terras no Paraguai: impactos e resistências. Relatório Parcial de Pesquisa Fundação de Amparo à Pesquisa do Estado de São Paulo (FAPESP), São Paulo, novembro de 2016.

PLOEG, Jan Bouwer van der; FRANCO, Jennifer; BORRAS JR., Sarurnino.Land concentration and land grabbing in Europe: a preliminar analysis. Canadian Journal of Development Studies, v. 36, n. 02, p. 147-162, 2015. 
REUTERS. Enter the new farmers. Global News Journal Reuters. Publicado em: 25 jun. 2008, disponível em: <http://blogs.reuters.com/global/2008/06/25/enter-the-newfarmers/>. Acesso em: 11 abr. 2017.

SASSEN, Saskia. Lands grabs today: feeding the disassembling of national territory. Globalizations, v. 10, n. 01, p. 25-46, 2013.

SAUER, Sérgio. Demanda mundial por terras: "land grabbing" ou oportunidade de negócios no Brasil? Revista de Estudos e Pesquisas sobre as Américas, v. 04, n. 01, 2010 .

SAUER, Sérgio. Corrida mundial por terras e direitos territoriais no Brasil. Revista Agriculturas, v. 08, n. 04, 2011.

SAUER, Sérgio; LEITE, Sérgio Pereira. Expansão agrícola, preços e apropriação de terra por estrangeiros no Brasil. Revista de Economia e Sociologia Rural da ESALQ, v. 50, n. 03, 2012.

SAUER, Sérgio; BORRAS JR., Saturnino 'Jun'. 'Land Grabbing' e 'Green Grabbing': uma leitura da 'corrida na produção acadêmica' sobre a apropriação global de terras. Revista Campo Território, Ed. Especial Land Grabbing, Grilagem e Estrangeirização de terras, n. 23, v. 11, p. 06-42, 2016.

SCHUTTER, Olivier de. How not to think of land-grabbing: three critique of large-scale investment in farmland. The Journal of Peasant Studies, n. 38, v. 02, p. 249-279, 2011.

VISSER, Oane. Finance and the global land rush: understanding the growing role of investiment funds in land deals and large-scale farming. Canadian Food Studies, v. 02, n. 02, p. 278-286, 2015.

VON BRAUN, Joachim; MEINZEN-DICK, Ruth. "Land Grabbing” by Foreign Investors in Developing Countries: risks and opportunities. IFRI Policy Brief, 2009.

WOERTZ, Eckart. The governance of Gulf agro-investments. Globalizations, v. 10, n. 01, p. 87-104, fev. 2013. 